\title{
Liderança Feminina: 0 Estado da Arte nas Publicações Brasileiras
}

\author{
Female Leadership: State of Art on Brazilian Publications
}

\author{
Maria Célia Bruno Mundim \\ Pontifícia Universidade Católica - Campinas \\ celiamundim@hotmail.com \\ Solange Muglia Wechsler \\ Pontifícia Universidade Católica - Campinas \\ wechsler@lexxa.com.br \\ Tatiana Nakano Primi \\ Pontifícia Universidade Católica - Campinas \\ tatiananakano@gmail.comr
}

\begin{abstract}
Resumo
O objetivo deste estudo foi avaliar a produção científica brasileira sobre liderança feminina. Neste sentido foram feitos levantamentos juntos às bases de dados eletrônicas Scielo, PePSIC e Index-Psi, assim como no banco de teses e dissertações da CAPES. As palavras-chaves utilizadas foram liderança e mulher, sem limitação de período. Foram selecionados 2 artigos no (PePSIC), 3 artigos no Index-Psi, 1 publicação no Scielo, 90 dissertações e 28 teses na CAPES. Os trabalhos foram analisados segundo os contextos pesquisados, tipo de pesquisa, tipo de instrumento, gênero dos autores, regiões das instituições com pesquisas sobre o tema, anos de publicação e áreas de conhecimento que mais enfocaram o tema. Dentre os resultados obtidos, destaca-se o aumento das publicações sobre o tema nos últimos anos, indicando que há interesse no estudo da liderança feminina.
\end{abstract}

Palavras-chave: mulheres; líder; pesquisa; liderança feminina

\begin{abstract}
The aim of this study was to evaluate the scientific production on female leadership. Consequently, we performed a search in electronic databases Scielo PePSIC and Psi-Index, as well as in the CAPES bank of theses and dissertations. The keywords used were leadership and woman, without a period delimitation. We selected two items in PePSIC, 3 articles in IndexPsi, 1 publication in Scielo, 90 dissertations and 28 theses in CAPES database. The papers were analyzed according to theme of research, kind of study, kind of instrument used, gender of authors, regions of the institutions with researches on the topic, years of publication and areas of knowledge that more frequently focused on the theme. Among the results, we highlighted the increase of publications on the topic in recent years, which indicates an interest in the study of female leadership.
\end{abstract}

Keywords: Women, Leader, Research, Female leadership 


\section{Introdução}

A ocupação das mulheres em posições de liderança, em diferentes segmentos, apresenta uma tendência, apesar desta ascensão ocorrer lentamente (VECCHIO, 2002). Dentre as explicações para este lento movimento, segundo alguns autores (CLOW \& RICCIARDELLI, 2011; ENGEN, LEEDEN \& WILLEMSEN, 2001; EAGLY \& JOHNSON, 1990), está ainda a existência da discriminação e do preconceito quanto às características tidas como femininas. Segundo estes autores, a mulher é vista como sensível, solícita, compreensiva e simpática enquanto os homens têm como estereótipo ser mais decisivos, competentes, racionais, assertivos, agressivos, independentes, enérgicos, dominantes e autossuficientes. Assim sendo, os homens tendem a ser percebidos como sendo mais compatíveis para os postos de comando.

A entrada da mulher no mercado de trabalho teve início com o advento da $\mathrm{I}^{\mathrm{a}}$ Guerra Mundial quando as mulheres passaram a ocupar posições de trabalhos, antes ocupadas pelos homens, que haviam sido convocados para atuarem nas frentes das batalhas (MIRANDA, 2006). Também a Revolução Francesa e o movimento feminista que continham ideias de igualdade e liberdade, além das conquistas na medicina, como, por exemplo, a descoberta da pílula anticoncepcional, foram fatores que influenciaram a ascendência das mulheres no ambiente público do trabalho (DEL PRIORE, 2004).

Além disso, as novas oportunidades oferecidas pelo mercado de trabalho após a II $^{\text {a }}$ Guerra Mundial contribuiu para o aumento da inserção feminina neste âmbito. O período de reconstrução do Pós-Guerra gerou uma ampliação do nível global de emprego levando ao crescimento significativo da produtividade, modernização dos processos produtivos, além da expansão da participação feminina, principalmente das que eram casadas, nos trabalhos em comércios, escritórios e indústrias como, por exemplo, as de tecidos (HOBSBAWM, 2002). Esta inserção feminina foi acompanhada por movimentos de mulheres que lutaram por direitos políticos, tais como o direito ao voto, os direitos trabalhistas e aos serviços públicos e particulares de atenção à maternidade e à saúde da mulher (CARVALHAL, 2002; CARVALHO, 2009; COELHO, SILVA, OLIVEIRA \& ALMEIDA, 2009).

Outras causas para o desenvolvimento do contexto acima exposto foi o aumento de famílias chefiadas por mulheres associada às mudanças nos padrões culturais referentes ao papel social da mulher cada vez mais voltado para a atividade remunerada (BRUSCHINI \& LOMBARDI, 2010; PINHEIRO et al., 2009). Os novos arranjos familiares de inserção no mercado de trabalho fizeram crescer a participação das cônjuges e das mulheres chefes de família no mercado (MONTALI, 2003; 2006). Contudo, tal crescimento não foi seguido pelo aumento salarial feminino, uma vez que a mulher continua a ter rendimentos inferiores aos dos homens (GIUBERTI \& MENEZES-FILHO, 2005). Em 2011, por exemplo, ao comparar a média anual dos rendimentos dos homens e das mulheres no Brasil, verificou-se que, em média, as mulheres ganharam em torno de $72.3 \%$ do rendimento recebido pelos homens, mesmo sendo elas chefes de família em $37 \%$ dos lares brasileiros (IBGE, 2012).

Para Eagly (2007) o aumento da escolarização das mulheres na atualidade, a maior partilha do trabalho doméstico e do acolhimento dos filhos com os maridos estão colaborando para o alcance da posição de liderança pelas mulheres. Por outro lado, a flexibilidade no trabalho (a escolha de horário e de local de trabalho) tem facilitado às mulheres a conciliação entre as demandas do trabalho com as demandas familiares (EIKHOF, 2012).

Segundo Casadei (2009) a abertura política do Brasil nos anos 80 pós-ditadura militar também fez surgir o movimento de mulheres, que se consolidou como uma força política e sindical. O movimento feminista inseriu-se em associações profissionais, sindicatos, partidos, tendo influência relevante na representação e criação dos primeiros conselhos estaduais de Direitos da Mulher nos estados de São Paulo, Minas Gerais e Rio de Janeiro em 1983 e na criação do Conselho Nacional dos Direitos da Mulher em 1985 (ABRAMO, 2010). Pinto (2001) ainda salienta que na década de 90 houve um forte discurso político nacional sobre os direitos das mulheres após a Constituinte de 1988, que assegurava um conjunto importante de direitos às mulheres, o que encorajou a participação das mulheres no campo político. Em 1997 foi criada a Lei de Cotas (Lei 9.504/97) que fixou as cotas mínimas (30\%) e máximas $(70 \%)$ de candidaturas por gênero. Em 2009 essa mesma Lei foi aprimorada por meio da Lei 12.034 para ampliar a inserção das mulheres nos partidos políticos (ARAÚJO, 2011). Como consequência, essa autora relata um aumento expressivo de mulheres eleitas nos vários cargos políticos, assumindo postos de liderança no Senado, Câmara dos deputados e governo estadual, nas eleições de 1998, 2002, 2006 e 2010.

Diversas definições sobre liderança são encontradas na literatura como a de Selznick (1992), que define a liderança como $\mathrm{o}$ ato de suprir necessidades em um contexto social e a de Wagner e Hollenbeck (2002), que referem a liderança como o uso de influência simbólica e não coercitiva para 
dirigir e coordenar um grupo. Entretanto, as conceituações estão mais relacionadas ao contexto empresarial e político, o que praticamente envolve como características centrais o processo de influência e o cumprimento de metas dentro de um grupo (CHIN, 2010). Apesar disto, estas características da liderança se estendem às outras esferas de atividades, tais como: esportiva, religiosa, saúde e educacional. Portanto é importante entender o conceito de líder mais amplo como sendo a pessoa que traz impacto ao seu meio e transforma um grupo, levando-o a lutar por um ideal maior (PUCCIO, MURDOCK \& MANCE, 2007).

A liderança transformacional é compreendida como sendo a que tem a capacidade de inspirar as pessoas, por meio de consideração individualizada e estímulo intelectual, procurando mudar suas percepções e motivações para que todos trabalhem em objetivos comuns (BERGAMINI, 2002; CHERRY, 2010). Embora Eagly (2007) e Tukk (2012) relacionem esse tipo de liderança mais as mulheres, para Duarte, D’Oliveira e Gomes (2009) não há associação entre gênero e o estilo transformacional de liderar.

Estudos comparativos entre homens e mulheres líderes e os seus estilos de liderança, o impacto do gênero do líder frente ao seu grupo dentre outros aspectos, podem ser encontrados em vários periódicos relacionados à liderança - The Leadership Quarterly, Journal of Leadership Studies, Strategy \& Leadership $e$ Leadership and Organization Development Journal. Nestes periódicos verifica-se que a maior parte dos estudos são realizados no contexto empresarial, com foco primordial para a função gerencial (CHATURVEDI et al., 2012; MCCOLL-KENNEDYA \& ANDERSON, 2005; MELO, 2004).

Também nestes estudos nota-se que, de modo geral, a metodologia qualitativa tende a ser mais empregada (OSPINA, 2004). Isto porque, segundo a autora, este tipo de pesquisa apresenta várias vantagens, dentre elas a flexibilidade para seguir as ideias imprevistas durante a investigação, o aumento de oportunidade para apoiar novas ideias e teorias, empiricamente, e o aumento de chance de estudos longitudinais sobre o fenômeno liderança. Outro benefício da pesquisa qualitativa de acordo com Parker (2011) é a maior proximidade do pesquisador com o campo investigado, o que possibilita uma melhor assimilação e análise do fenômeno nas circunstâncias em que ocorre. Por outro lado, Stentz, Clark e Matkin (2012) referem sobre a importância de se utilizar uma metodologia mista de pesquisa no estudo da liderança.

No que refere à produção científica nacional sobre liderança feminina, não há nenhuma pesquisa sobre a temática até o momento. Portanto, o objetivo deste estudo foi o de investigar as publicações brasileiras, como também, de teses e dissertações no portal Coordenação de Aperfeiçoamento de Pessoal de Nível Superior (CAPES), sem limitação de período. Desta maneira buscou-se entender a conceituação de liderança feminina nas mais diferentes áreas.

\section{Metodologia}

\section{Material}

Uma busca foi feita a partir das palavras-chaves liderança e mulher por meio do banco de teses da Coordenação de Aperfeiçoamento de Pessoal de Nível Superior (CAPES). Foram encontradas 51 teses e 166 dissertações e do total destas utilizou-se apenas 118 por focarem o tema inicial proposto, isto é, a liderança feminina.

Também se buscou artigos utilizando a palavrachave liderança em três bases de dados eletrônicas - o portal de Periódicos Eletrônicos de Psicologia (PePSIC), o Index-Psi e a Scientific Electronic Library (Scielo), pois o acesso à essas bases não disponibilizava o uso do termo liderança mulher.

\section{Procedimento}

Após a busca no banco de teses da CAPES, as teses e dissertações selecionadas foram avaliadas segundo os critérios: contexto pesquisado, tipo de pesquisa, tipo de instrumento, anos de publicação, gênero dos autores, regiões das instituições com pesquisas sobre o tema e áreas de conhecimento (de acordo com a classificação de áreas de conhecimento da CAPES). No acesso dos dados houve dificuldade, pois alguns trabalhos não continham a metodologia utilizada.

Quanto aos artigos encontrados no PePSIC, IndexPsi e Scielo não foram avaliados de acordo com os critérios acima adotados devido à quantidade reduzida de estudos nestes periódicos. Assim sendo, os artigos neles encontrados foram apenas descritos.

\section{Resultados}

Foram analisados ao todo 118 estudos, sendo 28 teses e 90 dissertações no banco de dados da CAPES. Sobre os tipos de pesquisa das teses e dissertações houve destaque para a pesquisa do tipo qualitativa $(55 \%)$. Os estudos teóricos $(10 \%)$, quantitativos (11\%), quantitativos com qualitativos $(5 \%)$ foram menos expressivos. $19 \%$ dos estudos não evidenciaram os métodos de pesquisa utilizados.

Quanto aos tipos de instrumentos utilizados nas bases de dados pode-se observar que a entrevista 
$(30 \%)$ foi mais utilizada, seguida pela análise documental (13\%), questionário (8\%), biografia $(7 \%)$ e observação (7\%). A pesquisa bibliográfica $(1 \%)$ e a escala $(1 \%)$ foram menos empregadas. Também, notase que um número significativo de teses e dissertações (19\%) não apresentaram os tipos de instrumentos utilizados.

A fim de esclarecer melhor os temas das pesquisas mais frequentes, foi feita uma análise de conteúdo das mesmas como apresentado nas Tabelas 1 e 2 .

Os títulos das pesquisas analisadas foram

Tabela 1. Títulos dos contextos político/sindical e organizacional das teses e dissertações.

\begin{tabular}{|c|c|}
\hline Contexto & Títulos das Dissertações e Teses \\
\hline Político/sindical & $\begin{array}{l}\text { A Luta pela Moradia em Alagados/ Tecendo a } \\
\text { política/Margarida, Margaridas: memória de } \\
\text { Margarida Maria Alves/ Do Segundo Sexo á } \\
\text { Segunda Onda/ Uniāo, Luta, Liberdade e } \\
\text { Resistência/Planejamento estratégico na área } \\
\text { sindical/ Participaçāo e consciência política/ } \\
\text { Mulheres de Elite em Movimento por Direitos } \\
\text { Políticos/ Por um novo cenário/Elas vieram para } \\
\text { ficar/ Educaçāo, Liderança e Consciência Política } \\
\text { de Mulheres Camponesas/ O Feminino na Sombra/ } \\
\text { Memória e História do Movimento de Mulheres no } \\
\text { Paraná/As operárias do ABC/ Tramando pequenos } \\
\text { fios de um longo tecido/A cultura instituinte dos } \\
\text { novos movimentos sociais/Militantes de clubes de } \\
\text { māes/ Lideranças femininas na luta pela terra/ As } \\
\text { mulheres trabalhadoras em luta/ A rede feto no } \\
\text { Timor-Leste/ Trajetórias em movimentos/ } \\
\text { Rompendo o Silêncio/ Lutadoras do Povo/ } \\
\text { Tajetórias de mulheres negras/ Mulheres na } \\
\text { liderança/ Movimento(s) na Roça/ A "voz" e o } \\
\text { "silêncio" de trabalhadoras rurais/ Mulher } \\
\text { comerciária e sindicalismo/ Saias, laços e ligas/ } \\
\text { Deslocamentos, vínculos afetivos e políticos/ } \\
\text { Lideranças Femininas Inter/Transnacionais na } \\
\text { Globalizaçāo/ Mulheres rurais organizadas/ Onde } \\
\text { Mora a Cidadania/ Mulheres em movimento/ } \\
\text { Aprender na prática/ Mulheres, política e cotidiano/ } \\
\text { De senhoras a mulheres trabalhadoras rurais/ } \\
\text { Memórias de mulheres dos movimentos sociais da } \\
\text { zona leste de Sāo Paulo/ Sindicatos/ A perspectiva } \\
\text { das lideranças politicas. }\end{array}$ \\
\hline Organizacional & $\begin{array}{l}\text { Inteligência emocional/ Mulheres no mundo dos } \\
\text { negócios/ Equidade de gênero em cargos de chefia/ } \\
\text { o Papel do Imaginário/ Mulheres Empreendedoras } \\
\text { em pequenas empresas/ Liderança nas grandes } \\
\text { empresas/ Estilos de pensar e criar/ Gênero e } \\
\text { trabalho/ Mulheres no Comando/ De ausente a } \\
\text { participante ativa na história/ Mulher e Poder/ A } \\
\text { Masculinizaçāo da Mulher Líder no Brasil/ A } \\
\text { publicitária em Sāo Paulo/ Desfeminilizaçāo } \\
\text { cultural e saúde/ Mulheres na Gerência/ Mulheres } \\
\text { profissionais bem sucedidas/ A Liderança Feminina } \\
\text { e a Corporalidade/ Gênero e Organizaçes/ } \\
\text { Relaçōes de gênero/ Atitudes e percepçāo de justiça } \\
\text { sobre a liderança feminina/ A face oculta da } \\
\text { liderança feminina. }\end{array}$ \\
\hline
\end{tabular}


Tabela 2. Títulos e contextos das teses e dissertações

\begin{tabular}{|c|c|}
\hline Contexto & Títulos das Dissertações e Teses \\
\hline Religloso & $\begin{array}{l}\text { Mulheres em revista/ Flores no concreto/ } \\
\text { Religião e mulher/ "Mulheres Todas Santas"/ } \\
\text { Mulher/ Sufismo, carisma e moralidade/ } \\
\text { Maria passa na frente/ Comunicação e } \\
\text { Relações de Gênero/ Um estudo do protesto } \\
\text { revolucionário do povo e das mulheres/ } \\
\text { Religião e Gênero/ Mulheres Iabás/ } \\
\text { Lideranças pentecostais femininas/ Ação } \\
\text { Pastoral das Irmãs Dominicanas/ Um estudo } \\
\text { da autoridade feminina/ A mulher na } \\
\text { hierarquia evangélica/ Entre a Politização da } \\
\text { Fé e o Carisma Conservador/ Gênero e } \\
\text { poder / A revista voz missionária. }\end{array}$ \\
\hline Comunitário & $\begin{array}{l}\text { As marisqueiras e a reserva extrativista Açaú- } \\
\text { Goiana/ Mulheres na Dança do Movimento } \\
\text { HIP HOP/ As mulheres da cidade D'Oxum/ } \\
\text { Quando a militância e a vida cotidiana se } \\
\text { (des)encontram/ Vestigios Recuperados/ } \\
\text { Mulheres na luta pela saúde/ Consciência e } \\
\text { constituição de valores comunitários/ } \\
\text { Mulheres e movimento de atingidos por } \\
\text { barragens/ Heroínas em luta na conquista de } \\
\text { suas glórias. }\end{array}$ \\
\hline Educacional & $\begin{array}{l}\text { Quando trabaio é ensinação/ Engenheiros, } \\
\text { mulheres, matemáticos/ Do arco ao poder/ } \\
\text { Mulheres na coordenação/ A Construção Da } \\
\text { Carreira De Reitoras/ A Trajetória de Reitoras } \\
\text { em Santa Catarina/ A constituição da cultura } \\
\text { dos movimentos sociais com processo } \\
\text { educativo. }\end{array}$ \\
\hline Esportivo & $\begin{array}{l}\text { O Processo de Inclusão das Mulheres nos } \\
\text { Jogos Olímpicos/ Capoeira Regional/ } \\
\text { Participação das mulheres na gestão do } \\
\text { esporte brasileiro/ Trajetória de mulheres- } \\
\text { referência no esporte nacional. }\end{array}$ \\
\hline Agricola & $\begin{array}{l}\text { Política de crédito rural com perspectiva de } \\
\text { gênero/ Mulheres nas águas/ Mulheres e } \\
\text { agroecologia/ Beneficios econômicos e } \\
\text { sociais a partir da participação em esquemas } \\
\text { associativos. }\end{array}$ \\
\hline Saúde & $\begin{array}{l}\text { A liderança feminina nos hemocentros/ Perfil } \\
\text { e Competências de Gerentes de Enfermagem/ } \\
\text { Gestão de Pessoal de Enfermagem por } \\
\text { Competências. }\end{array}$ \\
\hline Empreendedorismo & $\begin{array}{l}\mathrm{O} \text { empreendedorismo feminino/ O caminho } \\
\text { do empoderamento na superação da pobreza/ } \\
\text { A mulher empreendedora no setor } \\
\text { agropecuário. }\end{array}$ \\
\hline Cultural & $\begin{array}{l}\text { Conhecimento, poder e gênero/ Segurando as } \\
\text { pontas e tecendo as tramas/ Zulmira } \\
\text { D'Andrade Canavarros/ Imagens de } \\
\text { organizações de mulheres. }\end{array}$ \\
\hline
\end{tabular}

Maria Célia Bruno Mundim,Solange Muglia Wechsler e Tatiana Nakano Primi 
distribuídos conforme os contextos e pode-se verificar que a maioria das pesquisas relatam os contextos político/sindical (34\%). Também o ambiente organizacional (18\%) seguido pelo religioso (16\%) foram bastante estudados nas dissertações e teses. Os contextos com menos estudos foram: comunitário $(8 \%)$, educacional $(6 \%)$, esportivo $(4 \%)$, agrícola $(4 \%)$, cultural $(4 \%)$, saúde $(3 \%)$ e empreendedorismo (3\%). Todos os contextos foram categorizados por meio de temas que se aproximavam das áreas política/sindical, organizacional, religiosa, comunitária, educacional, esportiva, agrícola, saúde, empreendedorismo e cultural. Por exemplo, a pesquisa 'Mulher Comerciária e Sindicalismo' foi considerada pertencente à categoria político/sindical, já a dissertação intitulada 'Mulher e Poder' foi categorizada como do contexto organizacional, enquanto a pesquisa 'Religião e mulher' foi categorizada no contexto religioso. Na Tabela 1 encontram-se os estudos nos contextos político/sindical e organizacional. De modo geral, na área política/sindical são abordados estudos sobre movimentos sociais de luta e reivindicações por terra, por moradia, por direitos políticos por parte de mulheres operárias, negras, indígenas e rurais. Também são relatadas trajetórias políticas de mulheres que tiveram importante papel no movimento sindical e no movimento de mulheres, além da análise da militância feminina em sindicatos.

Quanto ao contexto organizacional, são descritos estudos que analisam a ascensão da mulher em cargos de comando, os desafios e os fatores determinantes da prática gerencial feminina, a gestão feminina em organizações de diversos segmentos, as percepções e atitudes dos subordinados frente à gestão feminina. Além destas pesquisas, há estudos que investigam as dificuldades encontradas pela mulher executiva, descrevem o perfil de mulheres bem sucedidas, seus estilos de pensar e criar, sua inteligência emocional e os etilos de liderança predominantes na gestão feminina.

A Tabela 2 mostra os títulos das pesquisas realizadas nos contextos religioso, comunitário, educacional, esportivo, agrícola, saúde, empreendedorismo e cultural. Os estudos da área religiosa envolvem questões relacionadas à exclusão das mulheres em posições de poder na hierarquia das religiões, a ideologia sobre a condição feminina na igreja evangélica e católica, o movimento de mulheres e o seu empoderamento em algumas religiões, as repercussões dos discursos religiosos na vida das mulheres e o comportamento feminino sob a influência religiosa em diferentes momentos históricos.

No contexto comunitário há estudos sobre a participação das mulheres em associações e movimentos em situações diversas como, por exemplo, na periferia de Salvador e na conservação do meio ambiente na reserva extrativista Açaú-Goiana. Já na área educacional existem estudos que analisam a trajetória de reitoras, a atuação e percepções de mulheres em cargos de coordenação e liderança em instituições educacionais, as mulheres nas áreas de exatas e a participação das mulheres em movimentos sociais como um processo educativo.

Quanto ao contexto esportivo, envolve pesquisas sobre a inserção do gênero feminino nos Jogos Olímpicos, a participação das mulheres na gestão do esporte, bem como as representações sociais das atletas de referência, das mestras e formandas em capoeira.

Ainda na Tabela 2 os estudos listados da área agrícola analisam o papel das mulheres pescadoras, pescadeiras, marisqueiras, agricultoras e quebradeiras de coco babaçu. Também há estudo que examina o impacto da linha de crédito Programa Nacional de Fortalecimento da Agricultura Familiar (Pronaf) destinado à mulher. As pesquisas do contexto de saúde visam identificar e caracterizar o perfil e as competências da liderança feminina na área de enfermagem. Enquanto os estudos relacionados ao empreendedorismo procuram verificar o estilo de liderança das mulheres empreendedoras, bem como o processo de empoderamento das empreendedoras no setor rural e agropecuário. Por fim, o contexto cultural incluso na Tabela 2 aborda a mulher afrodescendente e cultura yalodês, as mulheres mineiras chefes de domicílio do período de 1770 a 1880 , a trajetória de uma artista cuiabana e as organizações de mulheres no Rio Grane do Sul.

Quanto às áreas de conhecimento onde foram feitas mais pesquisas sobre o tema destacam-se as Ciências Humanas (Sociologia, Psicologia, História e Teologia) (69\%), sendo a maioria dos autores do gênero feminino (82\%). As Ciências Sociais Aplicadas (Administração) (15\%) também realizaram estudos, porém em menor quantidade. Na área de Linguística, Letras e Artes não há pesquisas sobre liderança feminina como pode ser visto na Tabela 3. 
Tabela 3. Áreas de conhecimento das dissertações e teses

\begin{tabular}{lcc}
\hline \multicolumn{1}{c}{ Áreas de Conhecimento } & Teses e dissertações \\
& F & $\%$ \\
Ciências Humanas & 82 & 69 \\
Ciências Sociais Aplicadas & 18 & 15 \\
Ciências Agrárias & 8 & 7 \\
Ciências da Saúde & 7 & 6 \\
Engenharias & 3 & 3 \\
Linguística, Letras e Artes & 0 & 0 \\
Total & 118 & 100 \\
\hline
\end{tabular}

Notou-se também que apesar de haver uma variação na quantidade de publicações no período de 1990 a 2011, os anos de $2002(\mathrm{~F}=13), 2009(\mathrm{~F}=17)$ e $2011(\mathrm{~F}=16)$ foram os que tiveram mais teses $\mathrm{e}$ dissertações publicadas acerca da liderança feminina, evidenciando aumento das publicações nos últimos anos. A região que mais pesquisou sobre liderança feminina foi a Sudeste (51\%) com dez instituições particulares e dez públicas com destaque para a Pontifícia Universidade Católica de São Paulo e a Universidade Gama Filho. Em segundo lugar está a região Nordeste $(22 \%)$ com uma instituição particular e sete públicas, tendo a Fundação Universidade Federal de Sergipe mais estudos a respeito da temática. Em seguida vem a região Sul (18\%) com 2 instituições particulares e cinco públicas, o Centro-Oeste $(7 \%) \mathrm{com}$ duas universidades públicas e três particulares e o Norte $(2 \%)$ com duas instituições públicas.

No que se refere às bases de dados Scielo, PePSIC e Index-Psi são relatados a seguir os artigos neles encontrados. A primeira base pesquisada foi o portal de Periódicos Eletrônicos de Psicologia - PePSIC (www.pepsic.bvs-psi.org.br), sendo encontradas 19 publicações com o termo liderança. Das publicações totais encontradas apenas 2 apresentaram o tema liderança feminina. São elas: 'Os discursos das mulheres em posições de poder' e 'Um estudo sobre as representações sociais de mulheres executivas: estilo de comportamento e de gestão'.

$\mathrm{O}$ artigo intitulado'“'Os discursos das mulheres em posições de poder' (NOGUEIRA, 2006) discute sobre a presença das mulheres em posição de poder, nos vários segmentos, com base nas diferentes teorias feministas. Para tanto, foram realizadas entrevistas individuais e não-diretivas, com dezoito mulheres portuguesas, com idades diversas, que ocupavam cargos de liderança em organizações estatais, particulares, do ramo industrial, científico e político. Foi feita a análise do discurso e concluiu-se que, apesar dessas mulheres não se assumirem como feministas, os seus discursos enquadram-se nas perspectivas feministas humanistas e nas de standpoint. Além disso, é sugerida uma maior discussão da problemática das mulheres em posição de liderança no sentido de desenfatizar as características psicológicas associadas ao gênero como argumentos para essa representação política das mulheres.

Na outra publicação do PePSIC, 'Um estudo sobre as representações sociais de mulheres executivas: estilo de comportamento e de gestão' (CORSINI \& SOUZA FILHO, 2004) foram comparadas as representações sociais de ambos os gêneros em relação às mulheres executivas. 47 indivíduos, sendo 20 estudantes universitários (de administração e de economia) e o restante de profissionais provenientes de uma empresa estatal e de uma empresa privada da cidade do Rio de Janeiro participaram do estudo. O instrumento utilizado foi um questionário com cinco questões abertas onde se procurou avaliar as representações que homens e mulheres fazem de 
modelos de gestão masculino e feminino. Constatou-se que a flexibilidade e a consistência predominam nas caracterizações dos estilos de gestão feminina e masculina, embora as participantes do gênero feminino não tenham feito distinção na caracterização dos estilos feminino e masculino de gestão. A diferença aparece nas expectativas para a gestão executiva, onde as mulheres apontaram que uma performance mais eficaz é aquela que se adapta às prescrições da empresa, com ênfase nas características individuais.

O Index-Psi (http://www.psicologiaonline.org.br/index_psi), que é uma base de dados de artigos de periódicos brasileiros em psicologia, organizada pelo Conselho Federal de Psicologia, apontou 55 publicações com o termo liderança, sendo que deste total 3 trabalhos eram sobre o tema proposto, ou seja, liderança feminina. Dois dos artigos são os mesmos que apareceram no PePSIC e o terceiro é intitulado 'Notícia: Maria Amelia Matos (1939-2005): Generosidade, Competência, Liderança' (TOMANARI, 2005) que refere sobre a trajetória de vida e profissional de uma das pioneiras da Psicologia no Brasil. Ela se destacou por ser uma pesquisadora de renome internacional, ligada à USP, que deixou relevantes contribuições sobre o Behaviorismo e um expressivo volume de publicações.

$\mathrm{Na}$ Scientific Electronic Library - Scielo (www.scielo.br) foi encontrada apenas uma publicação sobre liderança feminina, do total de 100 artigos surgidos com a palavra-chave liderança, intitulada 'Equipes gerenciadas por mulheres - representações sociais sobre gerenciamento feminino' (MOURÃO \& GALINKIN, 2008). Este estudo teve como objetivo apreender a maneira como as equipes que têm uma mulher como gerente estão construindo representações sociais sobre este gerenciar. Participaram 74 mulheres e 72 homens de equipes que trabalham com sete mulheres que ocupam altos cargos administrativos no Serviço Público Federal. Utilizou-se a associação livre de palavras, sendo as respostas analisadas pelo software EVOC. Os resultados indicaram que os participantes identificaram algumas características que as equipes atribuem ao gerenciamento feminino. Apontaram para uma forma de gestão voltada para as relações pessoais, pelo respeito pela pessoa e pela preocupação com a qualidade do trabalho, bem como pela inclusão.

\section{Discussão}

A liderança feminina deve ser estudada separadamente, pois o histórico da mulher por atingir posições de poder é distinto dos homens. Por sua vez, a liderança feminina deve ser entendida nos vários contextos que está representada, como pode ser observado neste estudo.

A partir dos resultados do presente estudo pode-se verificar que a liderança feminina não é um tema contínuo, pois houve uma variabilidade na quantidade de publicações sobre o tema durante a década de noventa e nos anos posteriores no banco de teses da Capes. Há uma tendência dos estudiosos da liderança se interessarem pelo tema (MOLLER \& GOMES, 2010), já que o crescimento das mulheres em posição de liderança em vários setores é observável (VECCHIO, 2002). O aumento das publicações sobre o tema se deu a partir do ano 2001 possivelmente com a ascensão da mulher em cargos de liderança, como por exemplo, a eleição da primeira mulher presidente no país em 2011.

No que refere ao contexto pesquisado, nota-se que o político/sindical foi o que mais se destacou, embora as pesquisas no setor organizacional e na esfera religiosa tenham sido expressivas. No setor político/sindical, por exemplo, foram encontradas pesquisas sobre a atuação das mulheres nos espaços dos sindicatos, o que talvez seja reflexo da significativa participação da mulher brasileira nos movimentos sindicais após o período de ditadura militar no país (CASADEI, 2009). Estudos sobre a mulher na política também se destacaram, provavelmente, pelo aumento significativo de mulheres eleitas nos vários cargos políticos nas eleições de 1998, 2002, 2006 e 2010 no Brasil (ARAÚJO, 2011). Este resultado demonstra uma preocupação distinta da literatura internacional (CHATURVEDI et al., 2012; MCCOLL-KENNEDYA \& ANDERSON, 2005; MELO, 2004) que refere ser o contexto empresarial o mais pesquisado sobre a liderança feminina.

Outro resultado refere-se ao tipo de pesquisa das teses. Sobressaíram os estudos qualitativos, o que é confirmado por Ospina (2004). Há pouquíssimos estudos quantitativos que comparam a liderança entre homens e mulheres ou os diferentes estilos de liderança entre as mulheres, que poderiam propiciar resultados por meio de amostras representativas. As pesquisas quantitativas também poderiam complementar as pesquisas qualitativas sobre liderança feminina por meio de instrumentos, tais como escalas e testes. O recurso mais utilizado nas pesquisas qualitativas foi à entrevista. Parker (2011) menciona que na pesquisa qualitativa há o estreito envolvimento do pesquisador com o campo investigado, o que permite uma compreensão mais crítica do fenômeno no contexto onde ele ocorre.

As Ciências Humanas foram às áreas de conhecimento com mais pesquisas realizadas sobre o 
tema, talvez pelo fato de serem encontradas nessas áreas mulheres mais preocupadas com este tema, uma vez que a maioria da autoria destes estudos é do gênero feminino. Entretanto, tais dados apontam que houve menos interesse em outras áreas de conhecimento para o estudo da liderança feminina. A produção de artigos sobre a temática em diferentes áreas seria interessante para favorecer a compreensão do tema por profissionais de diferentes formações.

Quanto às regiões que mais pesquisaram sobre liderança feminina destacou-se a Sudeste. A existência de núcleos de estudo de gênero nesta região como o Núcleo de Estudos de Gênero PAGU da Universidade Estadual de Campinas e o NEGUEM (Núcleo de Estudos de Gênero,Violência e Mulheres) da Universidade Federal de Uberlândia, bem como as linhas de pesquisa relacionadas ao gênero como, por exemplo, a linha de pesquisa 'Políticas públicas, gênero e redução das desigualdades' da Fundação Getúlio Vargas de São Paulo, facilitam o desenvolvimento de estudos focados na mulher.

A contribuição deste estudo foi ampliar a compreensão da liderança feminina em uma perspectiva mais ampla. Quanto à limitação apresentada pelo mesmo, refere-se a uma perspectiva nacional de pesquisas sobre liderança feminina. Pesquisas com dados de outros países sul-americanos seriam também importantes a fim de avaliar as preocupações sobre a mulher líder.

\section{Referências}

ABRAMO, Laís. Introdução In: Organização Internacional do Trabalho. Igualdade de gênero e raça no trabalho: avanços e desafios. Brasília:OIT, 2010, p. 15-48.

ARAÚJO, Clara. As mulheres e o poder político desafios para a democracia nas próximas décadas. In: BARSTED, Leila; PITANGUY, Jacqueline (Orgs.). O progresso das mulheres no Brasil - 2003-2010. Rio de Janeiro: CEPIA, 2011, p. 90-136.

BERGAMINI, Cecília. O Líder eficaz. São Paulo: Atlas, 2002.

BRUSCHINI, Cristina; LOMBARDI, Maria Rosa. Mulheres no mercado de trabalho: grandes números. [Disponível em $<$ http://www.fcc.org.br/bdmulheres>. Acesso em 23 de fevereiro de 2012.]

CARVALHO, Fernanda Mendes. Década de 30 - os anos de incertezas. [Disponível em $<$ http://www.administradores.com.br/informese/artigos/decada-de-30-os-anos-deincertezas/27596>. Acesso em 5 de abril de 2012.]

CARVALHAL, Terezinha Brumatti. A inserção da mulher no mercado de trabalho e a questão de gênero. Revista Pegada, v. 3, n. 1, p. 805 - 828, 2011.

CASADEI, Eliza Bachega. As questões de redistribuição e reconhecimento na imprensa feminista alternativa: o caso mulherio. Revista Alterjor, v.1, p. $1-11,2009$.

CHATURVEDI, Sankalp (et al.) The heritability of emergent leadership: Age and gender as moderating factors. The Leadership Quarterly, v. 23, n. 2, p. 219 - 232, 2012.

CHERRY, Kendra. Transformational Leadership What Is Transformational Leadership? [Disponível em

$<$ http://psychology.about.com/od/leadership/a/transfor mational.htm>. Acesso em 10 de dezembro de 2011.]

CHIN, Jean Lau. Introduction to the special issue on diversity and leadership. American Psychologist, v. 65, n. 3, p. 150 - 156, 2010.

CLOW, Kimberley A.; RICCIARDELLI, Rosemary. Women and Men in Conflicting Social Roles: Implications from Social Psychological Research. Social Issues and Policy Review, v. 5, n. 1, p. 191 226, 2011.

COELHO, Edméia de Almeida Cardoso (et al.). Integralidade do cuidado à saúde da mulher: limites da prática profissional. Escola Anna Nery Revista de Enfermagem, v. 13, n. 1, p. 154 - 60, 2009.

CORSINI, Leonora; SOUZA FILHO, Edson A. de. Um estudo sobre as representações sociais de mulheres executivas: estilo de comportamento e de gestão. Cadernos de Psicologia Social do Trabalho, v. 7, p. $67-80,2004$.

DEL PRIORE, Mary. História das mulheres no Brasil. Unesp, 2004.

DUARTE, Ana; D OLIVEIRA, Teresa; GOMES, Jorge. Imperium femininis...: Uma liderança de sucesso escondido. Revista Portuguesa e Brasileira de Gestão, v. 8, n. 3, p. 12 - 24, 2009. 
EAGLY, Alice H.; JOHNSON, Blair T. Gender and leadership style: A meta-analysis. Psychological Bulletin, v. 108, n. 2, p. 233 - 256, 1990.

EAGLY, Alice H. Female leadership advantage and disadvantage: resolving the contradictions. Psychology of Women Quarterly, v. 31, n. 1, p. 1 12, 2007.

EIKHOF, Doris Ruth. A double-edged sword: twentyfirst century workplace trends and gender equality. Gender in Management: An International Journal, v. 27, n. 1, p. 7 - 22, 2012.

ENGEN, Marloes L.; LEEDEN, Rien; WILLEMSEN, Tineke M. Gender, context and leadership styles: A field study. Journal of Occupational and Organizational Psychology, v. 74, n. 5, p. 581 - 598, 2001.

GIUBERTI, Ana Carolina; MENEZES-FILHO, Naércio. Discriminação de rendimentos por gênero: uma comparação entre o Brasil e os Estados Unidos. Economia Aplicada, v. 9, n. 3, p. 369 - 384, 2005.

HOBSBAWM, Eric. Era dos Extremos: o breve século XX; 1914-1991. 2a . Edição, São Paulo: Companhia das Letras, 2002.

IBGE. Principais destaques da evolução do mercado de trabalho nas regiões metropolitanas abrangidas pela pesquisa: Recife, Salvador, Rio de Janeiro, São Paulo e Porto Alegre 2003-2011. [Disponível em $<$ http://www.ibge.gov.br/home/estatistica/indicadores/t rabalhoerendimento/pme_nova/retrospectiva2003_201 1.pdf $>$. Acesso em 23 de fevereiro de 2012.]

MCCOLL-KENNEDY, Janet R.; ANDERSON, Ronald D. Subordinate-manager gender combination and perceived leadership style influence on emotions, self-esteem and organizational commitment. Journal of Business Research, v. 58, n. 2, p. 115 - 125, 2005.

MELO, Eleuní Antonio de Andrade. Escala de avaliação do estilo gerencial (EAEG): desenvolvimento e validação. Revista Psicologia: Organizações e Trabalho, v. 4, n. 2, p. 31 - 62, 2004.

MONTALI, Lilia. Relação família-trabalho: reestruturação produtiva e desemprego. São Paulo em Perspectiva, v. 17, n. 2, p. 123 - 135, 2003.

MONTALI, Lilia. Provedoras e co-provedoras: mulheres-cônjuge e mulheres-chefe de família sob a precarização do trabalho e o desemprego. Revista Brasileira de Estudos de População, v. 23, n. 2, p. 223 - 245, 2006.

MOURÃO, Tânia Maria Fontenele; GALINKIN, Ana Lúcia. Equipes Gerenciadas por Mulheres -Representações Sociais Sobre Gerenciamento Feminino. Psicologia: Reflexão e Crítica, v. 21, n. 1, p. $91-99,2008$.

NOGUEIRA, Maria da Conceição de Oliveira Carvalho. Os discursos das mulheres em posições de poder. Cadernos de Psicologia Social do Trabalho, v. 9 , n. 2, p. $57-72,2006$.

OSPINA, Sonia. Qualitative Research. [Disponível em

$<$ http://wagner.nyu.edu/leadership/publications/files/Q ualitative_Research.pdf $>$ Acesso em 10 de junho de 2011.]

PARKER, Lee D. Qualitative management accounting research: assessing deliverables and relevance. Critical Perspectives on Accounting, v. 23, n. 1, p. $54-70,2011$.

PINHEIRO et al. Retrato das desigualdades de gênero e raça. [Disponível em $<$ http://www.ipea.gov.br/sites/000/2/livros/2009/Livro RetratoDesigual.pdf $>$ Acesso em 23 de fevereiro de 2012.]

PINTO, Céli Regina Jardim Paradoxos da participação política da mulher no Brasil. Revista USP, v. 49, p. 98 - 112, 2001.

PUCCIO, Gerard J.; MURDOCK, Mary C.; MANCE, Marie. Creative leadership: Skills that drive change. San Diedo, CA: Sage, 2007.

SELZNICK, Philip. A liderança na administração: uma interpretação sociológica. Rio de Janeiro: FGV, 1992.

STENTZ, Jane E.; CLARK, Vicki Plano.; MATKIN, Gina S. Applying mixed methods to leadership research: A review of current practices. The Leadership Quarterly, v. 23, p. 1173 - 1183, 2012.

TOMANARI, Gerson Yukio. News: Maria Amelia Matos (1939-2005): generosity, competence, leadership. Psicologia: Teoria e Pesquisa, v. 21, n. 2, p. $255-256,2005$. 
Liderança Feminina: O Estado da Arte nas Publicações

Brasileiras

TUKK, Emily. Transformational Leadership in the Coming Decade: A Response to Three Major Workplace Trends. Cornell HR Review, p. 1 - 6, 2012.

VECCHIO, Robert P. Leadership and gender advantage. The Leadership Quarterly, v. 13, n. 6, p. $643-671,2002$.

WAGNER, John A.; HOLLENBECK, John R. Comportamento organizacional - criando vantagem competitiva. $3^{\text {a }}$ Edição, São Paulo: Saraiva, 2002.

Recebido em 20 de março de 2012. Aceito em 20 de abril de 2013. 